\title{
Spectroelectrochemical Study of Neptunium in Molten LiCl-KCl Eutectic
}

\author{
Ilya B. Polovov ${ }^{\mathrm{a}}$, Clint A. Sharrad ${ }^{\mathrm{b}}$, Iain May ${ }^{\mathrm{b}}$, Vladimir A. Volkovich ${ }^{\mathrm{a}}$, and \\ Boris D. Vasin ${ }^{\mathrm{a}}$ \\ ${ }^{a}$ Department of Rare Metals, Ural State Technical University, 620002 Ekaterinburg, Russia \\ b Centre for Radiochemistry Research, The University of Manchester, M13 9PL Manchester, \\ United Kingdom
}

Reprint requests to Dr. I. B. P.; E-mail: polovov@dpt.ustu.ru

Z. Naturforsch. 62a, 745 - 748 (2007); received June 11, 2007

Presented at the EUCHEM Conference on Molten Salts and Ionic Liquids, Hammamet, Tunisia, September 16-22, 2006.

Neptunium behaviour in an $\mathrm{LiCl}-\mathrm{KCl}$ eutectic melt at $723 \mathrm{~K}$ was studied using spectroelectrochemistry. Cathodic reduction of neptunium(IV)-containing melts led to the formation of $\mathrm{Np}$ (III) ions and then neptunium metal. Electronic absorption spectra of $\mathrm{Np}$ (IV) and $\mathrm{Np}$ (III) chloro species in $\mathrm{LiCl}-\mathrm{KCl}$ melt were recorded and resolved into individual Gaussian bands. The nature of neptunium complex ions in the melt is discussed.

Key words: Neptunium; Chloride Melts; Spectroscopy; Electrochemistry; Spectroelectrochemistry.

\section{Introduction}

Molten salts have many applications in actinoide processing and separations. Pyrochemical processes for the electrochemical separation of actinoides and fission products from irradiated nuclear fuels have been studied for several years. These technologies have been developed to a pilot plant scale at the Argonne National Laboratory, Argonne West, USA and at the Russian Institute of Atomic Reactors, Dimitrovgrad, Russia. Current research is focused on the next generation of pyrochemical processes for actinoide separations.

The development of safe and reliable separation technologies for actinoides in molten salts relies on a sound understanding of the key electrochemical processes. An increased awareness of in situ actinoide speciation could help underpin such electrochemical development. The most useful and direct information concerning coordination properties of actinoides in molten salts can be obtained from electronic spectroscopy. Combination of electrochemistry and spectroscopy in one spectroelectrochemical cell provides unambiguous information concerning the speciation of the studied element.

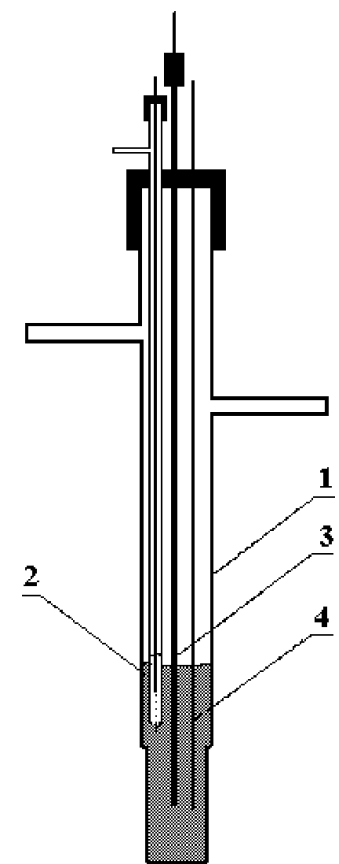

Fig. 1. Experimental spectroelectrochemical cell. 1, Silica optical cell; 2, chlorine reference electrode; 3, quartz capillary tube for chlorination; 4, glassy-carbon working electrode. 


\section{Experimental}

The experiments were carried out in a standard $1 \mathrm{~cm}$ silica optical cell attached to a silica tube (20 mm i.d.) with two side-arms (Fig. 1). A glassycarbon rod was used as working electrode. The other glassy-carbon or chlorine electrode in a quartz sheath served both as a counter and quasi-reference electrode and was separated from the bulk of the melt by a diaphragm.

The progress of electrode reactions was followed by in situ electronic spectroscopy and voltammetry measurements. Spectroscopic measurements were performed using a fibre optic spectrophotometer Avantes Avaspec-2048-2 with an Avalight DH-S deuteriumhalogen light source. A PAR/EG\&G Model 263A potentiostat/galvanostat was used to control the current passed through the cell and to monitor the red-ox potential of the working electrode. The current was set to $5 \mathrm{~mA}$.

Neptunium(IV)-containing samples were prepared by chlorinating hydrated neptunium(IV) oxide/chloride by hydrogen chloride in the melt. The neptunium stock solution in $1 \mathrm{M} \mathrm{HNO}_{3}$ had a neptunium(V) concentration of $0.1 \mathrm{~mol} / \mathrm{l}$. An aliquot of this solution (containing $20 \mathrm{mg}$ of ${ }^{237} \mathrm{~Np}$ ) was mixed with the stoichiometric amount of a $6 \mathrm{M} \mathrm{NaOH}$ solution to precipitate $\mathrm{NpO}_{2} \mathrm{OH} \cdot x \mathrm{H}_{2} \mathrm{O}$. The samples were centrifuged, the supernatant liquid decanted and the remaining solid washed with distilled water. This procedure was repeated once more, and the resulting solid was then dissolved in $1 \mathrm{M} \mathrm{HCl}$ to form $\mathrm{NpO}_{2} \mathrm{Cl}$. Several drops of HI solution ( $57 \mathrm{wt} \%$ ) were added to this solution to reduce $\mathrm{Np}(\mathrm{V})$ to $\mathrm{Np}(\mathrm{IV})$. The solution was evaporated to near dryness under a heat lamp. The residual was diluted with water, and the stoichiometric amount of $6 \mathrm{M}$ $\mathrm{NaOH}$ was added to completely precipitate $\mathrm{Np}(\mathrm{OH})_{4}$. The mixture was centrifuged, the supernatant liquid removed and the remaining solid washed with distilled water. The sample was centrifuged and the liquid decanted. The solid precipitate was dissolved in $1 \mathrm{M} \mathrm{HCl}$ to form an olive green solution of $\mathrm{NpCl}_{4}$ (the completeness of the reduction was confirmed by UV-visNIR spectroscopy). This solution was transferred into the high temperature spectroscopy cell. The cell was sealed and purged with argon. The solution was evaporated to dryness, giving the orange, solid $\mathrm{NpCl}_{4}$. The cell was then kept under vacuum with gentle heating for several hours to remove traces of moisture from the neptunium chloride.

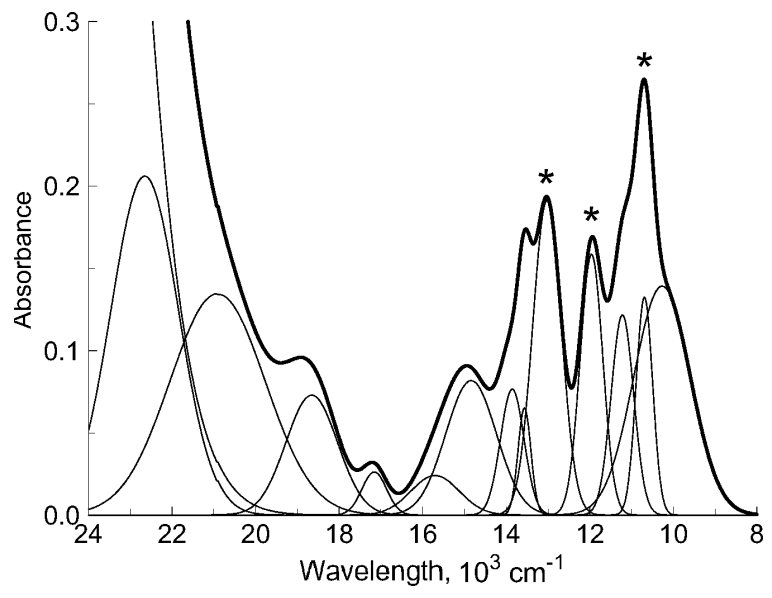

Fig. 2. Spectrum of $\mathrm{Np}(\mathrm{IV}),\left[\mathrm{NpCl}_{6}\right]^{2-}$, in an LiCl-KCl melt at $723 \mathrm{~K}$. Hypersensitive bands are marked with *. Neptunium(IV) concentration, ca. $0.015 \mathrm{~mol} / \mathrm{l}$.

All experiments were performed in an $\mathrm{LiCl}-\mathrm{KCl}$ eutectic (m.p. 633 K). Solid eutectic was added to the spectroscopic cell containing prepared neptunium chloride in an inert atmosphere glove box, closed with a stopper, transferred into an optical furnace and heated to $723 \mathrm{~K}$ under argon. Hydrogen chloride was bubbled through the melt for $1 \mathrm{~h}$ to convert any remaining oxide-containing neptunium species into chlorides.

\section{Results and Discussion}

The recorded spectrum of the $\mathrm{Np}(\mathrm{IV})$-containing chloride melt is shown in Figure 2. The spectral profile agrees very well with the data reported by Gruen et al. [1] and Barbanel' et al. [2]. The major bands situate at 530, 585, 665, 740, 770, 837 and $936 \mathrm{~nm}$ and correspond to the hexa-coordinated chloride complexes of neptunium(IV), $\left[\mathrm{NpCl}_{6}\right]^{2-}$.

By resolving the experimental spectrum into individual overlapping Gaussian bands, Fig. 2, it was possible to detect some hidden absorption bands and estimate the energies of the corresponding electronic transitions in the chloride ligand environment. The results of the resolution of the $\left[\mathrm{NpCl}_{6}\right]^{2-}$ spectrum are summarized in Table 1.

The obtained spectroscopic picture was compared with the energy levels diagram [3]. Neptunium(VI) has $\mathrm{f}^{3}$ electronic configuration, and the ground level is ${ }^{4} I_{9 / 2}$. Using the literature data concerning neptunium coordination in molten chlorides [3] and the results of our previous EXAFS spectroscopy measurements of U(III), also having $\mathrm{f}^{3}$ cofiguration, in an 


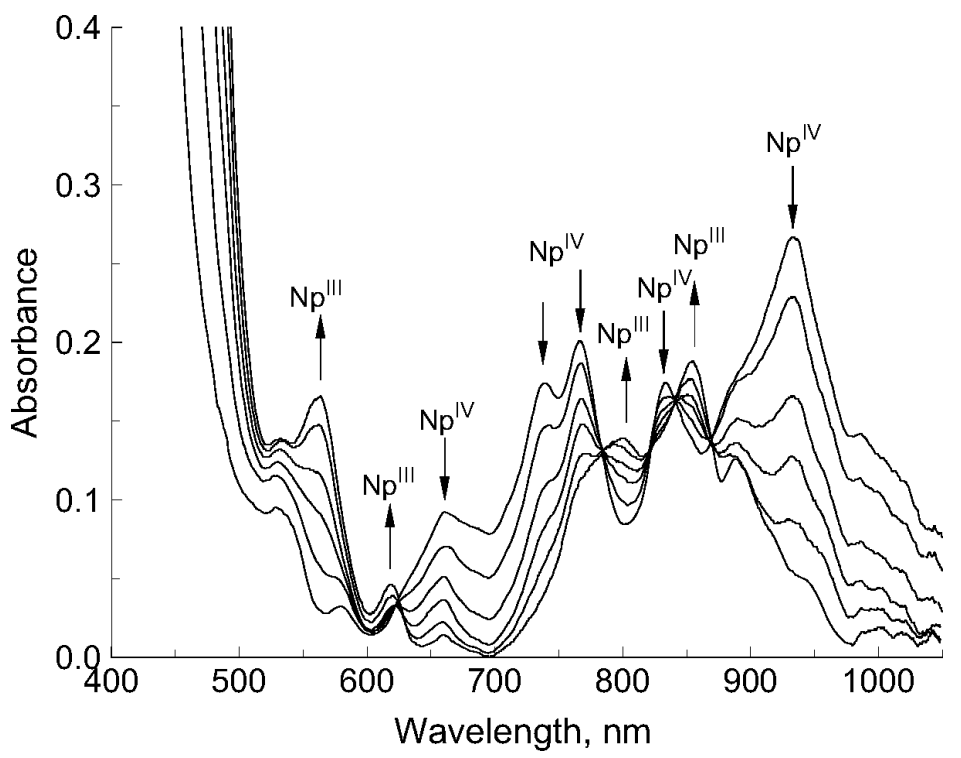

Fig. 3. Spectra recorded during electrochemical reduction of $\mathrm{Np}$ (IV) to $\mathrm{Np}$ (III) in an $\mathrm{LiCl}-\mathrm{KCl}$ eutectic melt at $723 \mathrm{~K}$. Initial concentration of neptunium(IV), ca. $0.015 \mathrm{~mol} / \mathrm{l}$; total time of reduction, $1280 \mathrm{~s}$; current, $5 \mathrm{~mA}$.
Table 1. Parameters of individual absorption bands in a resolved $\left[\mathrm{NpCl}_{6}\right]^{2-}$ spectrum.

\begin{tabular}{ccc}
\hline Energy, $\mathrm{cm}^{-1}$ & Half-height width, $\mathrm{cm}^{-1}$ & Relative intensity, $\%$ \\
\hline 10273 & 1591 & 68.3 \\
10697 & 465 & 64.4 \\
11225 & 647 & 60.1 \\
11969 & 634 & 77.7 \\
13036 & 807 & 93.7 \\
13574 & 357 & 31.6 \\
13864 & 635 & 35.7 \\
14837 & 1544 & 38.5 \\
15620 & 1518 & 11.1 \\
17181 & 685 & 12.6 \\
18677 & 1449 & 34.1 \\
21262 & 3057 & 78.9 \\
22710 & 1809 & 100.0 \\
\hline
\end{tabular}

(Li-K)Cl melt at $723 \mathrm{~K}$ [4], we can conclude that neptunium(IV) in an $\mathrm{LiCl}-\mathrm{KCl}$ eutectic forms octahedrally coordinated complex $\left[\mathrm{NpCl}_{6}\right]^{2-}$ ions.

It is well known that the task of assigning all resolved Gaussian bands to individual f-f electronic transitions (including their vibronic components) cannot be solved due to the high number of Stark's and $J$ levels. However, most intense, so-called "hypersensitive" transitions, can be assigned [5].

According to the basic principle of determining hypersensitive transitions $(\Delta J=2)$ and the energy level diagram, there are two major hypersensitive transitions in the studied wavelength range, ${ }^{4} \mathrm{I}_{9 / 2} \rightarrow{ }^{4} \mathrm{~F}_{5 / 2}$ and ${ }^{4} \mathrm{I}_{9 / 2} \rightarrow{ }^{4} \mathrm{G}_{5 / 2}$. For $\mathrm{Np}(\mathrm{IV})$ they are situated at 10000 and $11800 \mathrm{~cm}^{-1}$, respectively. Taking into account the "blue" shift of the peaks resulting from the
Table 2. Parameters of individual absorption bands in a resolved $\left[\mathrm{NpCl}_{6}\right]^{3-}$ spectrum in an LiCl-KCl melt at $723 \mathrm{~K}$.

\begin{tabular}{lccl}
\hline Energy, & $\begin{array}{c}\text { Half-height } \\
\text { width, } \\
\mathrm{cm}^{-1}\end{array}$ & $\begin{array}{c}\text { Relative } \\
\text { intensity, } \\
\%\end{array}$ & $\begin{array}{l}\text { Positions of Np(III) bands } \\
\text { in CsCl melt at 973 K } \\
\text { (data from [2]) }\end{array}$ \\
\hline 10740 & 628 & 40.7 & 10420 \\
11173 & 405 & 65.5 & 11100 (shoulder) \\
11672 & 515 & 100.0 & 11650 \\
12225 & 999 & 71.0 & 12620 \\
12947 & 1077 & 66.9 & 13140 \\
15124 & 636 & 9.4 & 15480 \\
16176 & 638 & 31.3 & 16100 \\
17660 & 1157 & 88.4 & \\
18778 & 1763 & 75.4 & \\
\hline
\end{tabular}

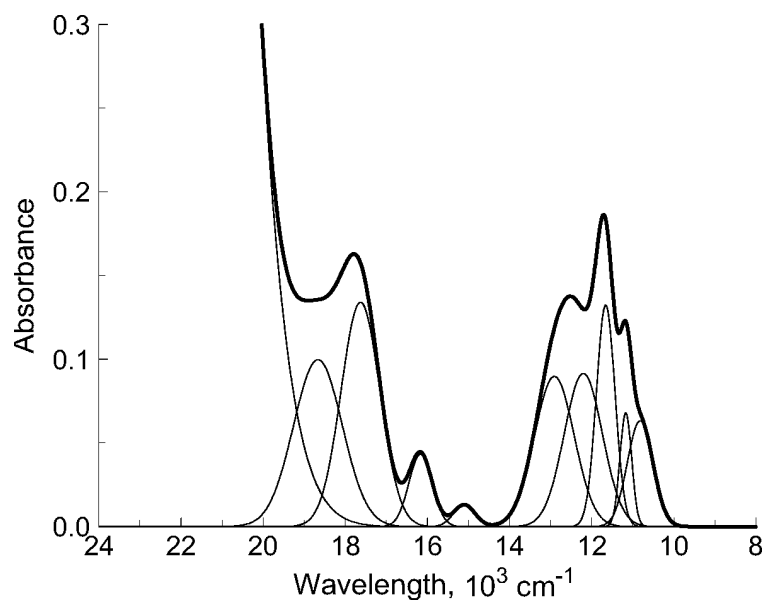

Fig. 4. Spectrum of $\mathrm{Np}(\mathrm{III}),\left[\mathrm{NpCl}_{6}\right]^{3-}$, in an $\mathrm{LiCl}-\mathrm{KCl}$ melt at $723 \mathrm{~K}$. 
nephelauxetic effect, the absorption bands at 10200 $11200 \mathrm{~cm}^{-1}$ and ca. $11970 \mathrm{~cm}^{-1}$ can be reliably attributed to these hypersensitive $\mathrm{f}-\mathrm{f}$ transitions and associated fine structure bands. Another intensive absorption peak at ca. $13030 \mathrm{~cm}^{-1}$ is likely associated with a ${ }^{4} I_{9 / 2} \rightarrow{ }^{4} G_{7 / 2}$ electronic transition which satisfies two additional requirements for hypersensitive transitions ( $\Delta L=2$ and $\Delta S=0$ ). The nature of other peaks is not obvious. For example, at relatively high energies (wavenumbers) bands arising from $\mathrm{f}-\mathrm{d}$ electronic transitions are also possible.

The progress of neptunium(IV) electroreduction was followed by in situ electronic absorption spectroscopy. As can be seen in Fig. 3 the intensities of the bands corresponding to $\mathrm{Np}$ (IV) decrease. At the same time new peaks at 565, 790, 660, 800, 855 and $890 \mathrm{~nm}$ appear and grow. There are 5 isosbestic points at 625 , $785,822,842$ and $870 \mathrm{~nm}$ (Fig. 3), indicating that the total concentration of neptunium in the melt remained constant during the neptunium(IV) electoreduction: $\left[\mathrm{NpCl}_{6}\right]^{2-} \rightarrow\left[\mathrm{NpCl}_{6}\right]^{3-}$. The spectral profile of the final obtained spectrum is typical of the neptunium(III) chloro complex $[1-3,6]$. After complete conversion of $\mathrm{Np}$ (IV) to $\mathrm{Np}$ (III) the electrolysis was continued and the intensity of the $\mathrm{Np}(\mathrm{III})$ spectrum began to decrease in the entire wavelength range due to reduction of $\mathrm{Np}$ (III) ions to neptunium metal.

The spectrum attributed to $\mathrm{Np}(\mathrm{III})$ was also resolved into individual Gaussian bands (Fig. 4, Table 2). Table 2 also lists $\mathrm{Np}(\mathrm{III})$ band positions in a CsCl-based melt at $973 \mathrm{~K}$ (after Barbanel' et al. [2]), included for comparison. $\mathrm{Np}$ (III) spectra have also been previously

[1] D. M. Gruen, S. Fried, P. Graf, and R. L. McBeth, in: Proceedings of the $2^{\text {nd }}$ International Conference on Peaceful Uses of Atomic Energy, U.N., Geneva 1958, p. 112.

[2] Yu. A. Barbanel', V.P. Kotlin, V. V. Kolin, and G. P. Chudnovskaya, Sov. Radiochimiya 17, 929 (1975).

[3] Yu. A. Barbanel', Coordination Chemistry of fElements in Melts, Energoatomizdat, Moscow 1985 (in Russian).

[4] V. A. Volkovich, I. May, C. A. Sharrad, H. Kinoshita, recorded in an LiCl- $\mathrm{KCl}$ melt at $873 \mathrm{~K}$ [1]. The spectra reported in the literature $[1,2]$ are very similar to the spectrum recorded here thus confirming that the reduction of $\mathrm{Np}(\mathrm{IV})$ went to completion. To our knowledge this is the first time the spectrum of $\mathrm{Np}$ (III) was measured in an $\mathrm{LiCl}-\mathrm{KCl}$ melt at $673 \mathrm{~K}$.

Neptunium(III) has $\mathrm{f}^{4}$ electronic configuration with ${ }^{5} \mathrm{I}_{4}$ ground state. The energies of the spectral bands were compared with the energy level diagrams [3]. Unfortunately the only hypersensitive band ${ }^{5} \mathrm{I}_{4} \rightarrow{ }^{5} \mathrm{I}_{6}$ expected for the $\mathrm{f}^{4}$ configuration is out of the studied wavelength range. Unambiguously assigning resolved Gaussian bands to specific electronic transitions is a complicated task and requires performing additional theoretical calculations and modelling.

\section{Summary}

The behaviour of neptunium chloro species in an LiCl-KCl eutectic melt at $723 \mathrm{~K}$ was studied for the first time, using spectroelectrochemistry. Neptunium(IV) chloride dissolves in the $\mathrm{LiCl}-\mathrm{KCl}$ melt producing $\left[\mathrm{NpCl}_{6}\right]^{2-}$ ions. Electrochemical reduction of $\mathrm{Np}(\mathrm{IV})$ on a glassy-carbon electrode results in the formation of $\left[\mathrm{NpCl}_{6}\right]^{3-}$ ions and then leads to the deposition of neptunium metal. Electronic absorption spectra of $\mathrm{Np}(\mathrm{IV})$ and $\mathrm{Np}$ (III) complex chloride ions were measured between 400 and $1100 \mathrm{~nm}$ and resolved into individual overlapping bands.

\section{Acknowledgements}

I. B. P. thanks INTAS (Grant No. 03-55-1453) for financial support.

I. B. Polovov, A. I. Bhatt, J. M. Charnock, T. R. Griffiths, and R. G. Lewin, in: Recent Advances in Actinoide Science (Eds. R. Alvarez, N. D. Bryan, I. May), RSC Publishing, London 2006, p. 485.

[5] D. E Henry, R. L. Fellows, and G. R. Choppin, Coordinat. Chem. Rev. 18, 199 (1976).

[6] V. V. Kolin, Yu. A. Barbanel', V.P. Kotlin, A. N. Smirnov, A. A. Lumpov, and Yu. I. Gavrish, Sov. Radiochimiya 26, 525 (1984). 